\title{
The Use of Index Approach for Enterprise Energy Strategy Formation
}

\author{
Melnik A.N. \\ Kazan Federal University, Kazan, 420008, Russia \\ Lukishina L.V. \\ Kazan Federal University, Kazan, 420008, Russia \\ Email address: Ilukishina@mail.ru
}

Doi:10.5901/mjss.2014.v5n18p289

\begin{abstract}
Constantly increasing competition in the markets of goods and services determines the need for new ways to improve the competitiveness of the enterprises and its products. The improving of production efficiency depends on various factors, including the energy factor. The rising of energy costs share in total cost of products manufactured by industrial enterprisers, have an increasing impact on the prices level and the products competitiveness. Further improvement of fuel and energy use efficiency will be largely determined by the success of energy management. The article describes the methodological basis for the industrial enterprise energy strategy formation based on the index approach.
\end{abstract}

Keywords: competitiveness, energy costs, energy strategy, index approach

\section{Introduction}

Globalization of world economy is accompanied by increased competitive pressure on industrial enterprisers in different countries. Under these conditions, the effective use of all resources becomes their top priority [1, 2]. High level of energy consumption is becoming one of the most important factors that limits substantially the competitiveness of products produced by various manufacturers. All this fully applies to the Russian economy, suggesting the need for new approaches to industrial enterprisers' energy costs managing.

One of the possible solutions of this problem is the development of the energy management system and its implementation in enterprisers of different branches and spheres of economy [3-6]. Of particular interest is the study of various aspects of enterprisers' energy strategy formation. However, the lack of scientific support of energy costs management, which design would reflect a systemic impact of the energy factor on the results of industrial enterprises production and economic activity and the competitiveness of their products, is one of the major factors significantly limiting improving producers' efficiency.

\section{Method}

Different approaches to the implementation of activities, aimed at energy efficiency improving and energy costs reducing, are considered by many researchers from various countries. Energy management systems are actively implemented in industry for a number of years. [7] However, most of them aimed at solving basically only the energy costs operational control tasks. [8] Some researchers note that in order to increase the efficiency of the energy management system and to make possible to implement the energy saving potential on the enterprise, energy management system must be integrated into the strategic management system [9]. However, it should be noted that so far many of the problems associated with the methodological support of the industrial enterprises energy strategy formation remain undeveloped. Many unsolved issues related to the formation of a system of indicators for economic evaluation energy use efficiency. There is also no methodical basis for assessing the impact of energy efficiency on the final business results. To solve stated problems index approach for comprehensive economic analysis of possible consequences of accepted decisions was used. 


\section{Results}

Under the conditions of constantly increasing competition among various manufactures the formation of energy strategy could be considered as one of the possible directions of the reduction of energy costs in the total product cost. Thus energy strategy is understood as a set of measures aimed at achieving the objectives of the enterprise functioning based on more effective use of all types of energy recourses. It should be mentioned, that the design of energy strategy in modern conditions is becoming one of the priorities of the enterprise energy department.

It is especially relevant for Russian enterprisers, because under the previous conditions of centralized economy energy departments were mainly responsible for technical tasks including enterprise provision of all types of energy, maintenance and repair of electrical equipment, personnel training methods of safe handling of equipment, planning and management of the energy sector, the development of the energy balance and others. However, the development of market relations, accompanied by increased competition between different manufacturers, necessary addresses the new challenges to energy management, aimed at improving the efficiency of energy services in the changed circumstances. These include, firstly, the formation of new approaches to energy resources management system construction, aimed at improving its use and increasing enterprise competitiveness. The solution to this problem possible through the introduction of an energy management system, the internal and external energy audits and enterprise energy strategy development, aimed at the implementation of an overall strategy by improving the efficiency of energy use.

Secondly, electricity and thermal energy supplier selection. Real opportunity to choose supplier of energy products, taking into account the need to ensure an appropriate level of security of supply at the lowest cost, is associated with the formation of a competitive energy market and with appeared possibility of purchasing electricity in the wholesale market. Furthermore, in the present conditions other alternatives in part of enterprise energy provision have appeared, including, for example, rent or purchase of generating capacity, individual or equity participation in the creation of generation companies, etc. [10-12]. That is why on first place comes the need for analysis and selection of suppliers providing the appropriate level of security of supply at the lowest cost.

Thirdly, structure and modes of enterprise energy consumption control in order to provide flexibility and stability of the power system and maintain the level of energy consumption at a minimum level in the given time period.

Fourth, training and retraining energy services personnel in order to adjust their work to changing conditions and to better energy management and energy audit understanding.

At the same time the enterprise energy strategy formation is a complex task that integrates separate energy service activities. It is useful to consider a number of fundamental principles during the development of the energy strategy. (fig. 1).

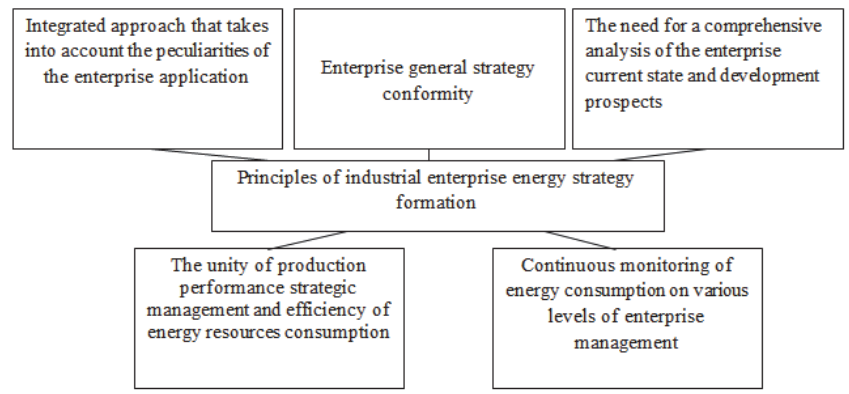

Fig.1. Principles of industrial enterprise energy strategy formation

Our approach to enterprise energy strategy formation could be represented as a multi-stage model, which includes the implementation of a number of interrelated activities (fig. 2.).

Energy strategy could be implemented in different ways on the basis of a complex of activities performance. At the same time the implementation of each direction of the energy strategy is associated with the need of financial recourses on investment and operating costs in the hope of getting some results. But their achievement is limited to a range of external and internal factors. In this connection there is the problem of assessing and selecting the most preferred embodiments of the strategy of the entire spectrum of potential alternatives. This makes it necessary to establish a system of assessing the impact of energy efficiency on the final business results. For this case index approach based on 
the construction of interlocking proportions can be used. Its essence in relation to the solving problem is the following.

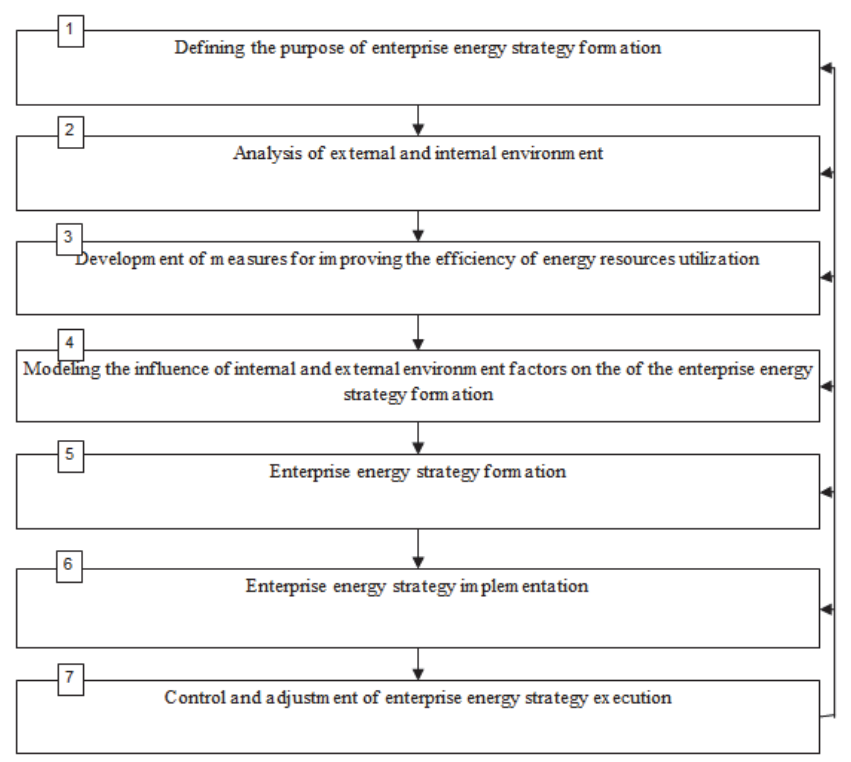

Fig.2. Multistage model of enterprise energy strategy

On the one hand, the most important result of more efficient use of energy resources is the increase of production efficiency, expressed in terms of human labor and the fixed assets (FA) better use with the concurrent increase in production volumes. Their positive trend suggests the need to increase labor productivity, return on assets and output maintaining the level of energy resources consumption at the existing level. This could be represented by the following index ratios:

$I_{L P}>1, I_{R A}>1, I_{0}>1$,

where lLP - labor productivity index, IRA - return on assets index, lo - output index.

On the other hand, labor productivity growth suggests need to improve the installed power of production. Exactly through the use of modern technological processes and equipment, a real possibility to release of living labor appears. However, installed power of production increase entails growth of fixed assets energy consumption as a result of the increase in total energy consumption. It could be represented by the following index ratios:

$I_{P L}>1, \quad I_{P F A}>1, \quad I_{P}>1$,

where $I_{P L}$ - installed power of labor, IPFA - installed power of fixed assets, IP - energy consumption index.

However, the unlimited and uncontrolled growth of the individual components of the expression (2), which defines the necessary conditions to ensure production efficiency due to the energy factor, may enter into conflict with the individual components of the expression (1), which reflects the general conditions of production efficiency. Therefore, to reconcile the dynamics of change of indices mentioned above the following relations must be satisfied:

$I_{L P}>I_{P L}, I_{R I}>I_{P F A}, I_{O}>I_{P}$.

Index ratios presented in equation (3) compliance, will testify the efficiency of production as a result of energy resources better use. If specified index will not be executed, then the reduction of energy production will not be accompanied by an increase in production efficiency. Hence we could make a very important conclusion, that a necessary condition for enterprise energy strategy formation, aimed at overall strategy realization, is the compliance of the index ratios presented in equation (3).

We have determined the effect of energy use efficiency increase on the final results of one of the Russian machine-building enterprises for the purpose of experimental validation of proposed approach. Assessment results of the impact of energy use efficiency to improvement of production efficiency in general using mentioned above proportions are shown in Table. 1. According to analysis of the results obtained during the study period the energy intensity of production has decreased. The output increase was accompanied by a decline in energy resources consumption. In addition, during 
this period the growth rate of labor productivity exceeded growth rate of installed power of labor, indicating more efficient use of energy resources.

Table 1: Results of various indicators change index calculation

\begin{tabular}{|c|l|c|c|c|c|c|}
\hline $\mathrm{N}$ & Index designation & 2009 year & 2010 year & 2011 year & 2012 year & 2013 year \\
\hline 1 & Production energy intensity index, $\mathrm{I}_{p e}$ & 1 & 0,85 & 1,03 & 1 & 0,95 \\
\hline 2 & Output index, $\mathrm{I}_{0}$ & 1 & 1,10 & 0,98 & 0,93 & 1,12 \\
\hline 3 & Energy consumption index, $\mathrm{I}_{\mathrm{c}}$ & 1 & 0,94 & 1,01 & 0,93 & 1,07 \\
\hline 4 & Installed power of labor index, $\mathrm{I}_{p l}$ & 1 & 0,95 & 1,06 & 1,05 & 1,07 \\
\hline 5 & Labor productivity index, $I_{p}$ & 1 & 1,11 & 1,03 & 1,05 & 1,12 \\
\hline
\end{tabular}

The analysis of results, obtained due to the study of different indicators index ratios could be used for the formation of the possible directions of enterprise energy strategy implementation. It is also very useful for justification of activities selection, which contributes to more efficient use of energy resources, as well as production efficiency improvement, thus providing its most intensive growth.

\section{Conclusion}

Under the conditions of world economy globalization and increased competition industrial enterprises should pay special attention to energy efficiency improvement. In this case energy strategy seemed as a managerial tool aimed at improving energy resources use efficiency and reducing the quantity of energy costs in the total cost of production. Using an index approach for assessing the impact of energy efficiency on the results of the company promotes the adoption of the most informed management decisions during development and selection the ways of implementation energy strategy directions.

\section{Acknowledgements}

This work was funded by the subsidy allocated to Kazan Federal University for the state assignment in the sphere of scientific activities.

\section{References}

Kirshin I.A., Gareev B.R. Theory of constraints in value based cost management // World Applied Sciences Journal (Economics, Management and Finance), 27, 2013, pp. 102-106.

Kirshin I.A. Modeling the long-term trend of accumulation of knowledge.// Life Science Journal, 11(65), 2014, pp. 482 - 486.

Melnik A.N., Lukishina L.V., Khabibrakhmanov R.R. Methodological Foundations of the Formation of the Energy Strategy of an Enterprise.// World Applied Sciences Journal, 23 (8), 2013, pp. 1085-1089.

Sadriev A. R. Problems and Prospects of Networking Mechanism Using in Energy Systems Innovation Development // Middle-East Journal of Scientific Research, 17 (10), 2013, pp. 1453-1456.

Melnik A.N.; Ermolaev K.A.; Antonova N.V.. Stages in Formalizing Energy Conservation and Efficiency Management in Industrial Enterprises.//Mediterranean Journal of Social Sciences, 5 (12), 2014., p. 173.

Anisimova T. Yu. Analysis of Standards in Energy Management.// Middle-East Journal of Scientific Research, 13(5), 2013, pp.654-657.

Muller D., Marechal F., Wolewinski T., Roux P. An energy management method for the food industry.// Appl Therm Eng, 2, 2007, pp. 2677-2686.

Weidong F., Wei,H., Kunya W., Huoyin L., Zhiha J. A method to establish and run management system for energy/l. Energy Procedia, 5 , 2011, pp. 1584-1588.

Vered Blass, Charles J. Corbett, Magali A. Delmas, Suresh Muthulingam. Top management and the adoption of energy efficiency practices: Evidence from small and medium-sized manufacturing firms in the US //Energy, 65, 2014, pp. 560-571.

Engoian A. Industrial and institutional restructuring of the Russian electricity sector: Status and issues// Energy Policy, 34, 2005, pp. 3233-3244

Nepal R., Jamasb T. Reforming the power sector in transition: Do institutions matter? //Energy Economics, 34, 2012, pp. $1675-1682$.

Nagayama $\mathrm{H}$. Electric power sector reform liberalization models and electric power prices in developing countries An empirical analysis using international panel data.// Energy Economics, 31, 2009, pp.463-472. 